\title{
Del libro tradicional al libro alternativo: formas, materiales y variantes denominativas
}

\author{
Celso Martínez Musiño \\ Dokumenta Consultoría e Integraciones, México
}

REVIEW

\begin{abstract}
Resumen
Objetivos. Describir el proceso de transición del libro tradicional al libro alternativo; investigar la conversión denominativa de los libros de artista, o el libro objeto (y otras maneras de mencionarlos) al libro alternativo; referir los materiales utilizados en la elaboración de los libros alternativos como objetos escriturales.

Método. Estudio, descriptivo-aproximativo, cuyo procedimiento de la investigación fue el siguiente: investigación documental y visitas a museos; selección y análisis de los datos compilados; redacción de los resultados y las conclusiones. Discusión. El término libro alternativo, tiene su origen tanto en el libro tradicional como en otras manifestaciones artísticas libro arte objeto, los libros de viaje o, los libros de artista, por mencionas algunos y, por otro lado, algunas obras, producto de los artistas, presentan formatos tan diversos como los orígenes de libros manuscritos o impresos.

Resultados. Del estudio indican que los libros alternativos tienen distintos orígenes denominativos, siendo los libros tradicionales el punto de inicio del libro objeto.

Conclusiones. De un conjunto de denominaciones, el término libro alternativo es el vocablo que la comunidad artística de las obras analizadas para nuestra investigación ha adoptado. Por otra parte, la forma de los libros tradicionales puede cambiar casi en su totalidad, tanto por el rediseño o intervención de los artistas, así como por la diversidad de materiales y técnicas utilizadas.
\end{abstract}

Palabras clave

Libro; libro alternativo; objetos escriturales

\section{From the traditional book to the alternative book: forms, materials and word variants}

Abstract

Objectives. Describes the process of transition from traditional book to alternative book; to investigate the word conversion of artists' books, or book object (and other ways to mention) the alternative book, and; to refer the materials used in the production of alternative scriptural books as objects.

Method. Descriptive study, of firsts approximation, whose research procedure was as follows: desk research and visits to museums; selection and analysis of data collected; writing of the results and conclusions.

Discussion. The term alternative book has its origins as the traditional book as other book art object, travel books or books artist artistic manifestations, etc., on the other hand, some works, product of artists, have such different formats as sources as the origin to produce manuscripts or printed books.

Results of the study indicate that alternative books have different verbal origins, traditional books being the starting point of the book object.

Conclusions. A set of denominations, the alternate book is the term that the artistic community of the works analyzed for our research has adopted. Moreover, the form of traditional books can change almost entirely, so the redesign or intervention of artists, as well as the diversity of materials and techniques used.

Keywords

Alternative book; book; writing objects 


\section{Introdução}

Esta investigación surge a partir del desarrollo del Proyecto Los soportes, las superficies y los visualizadores de la escritura: enfoques y materiales (Martínez Musiño, 2015b), en el cual después de observar una diversidad de materiales utilizados en las obras de arte y la aparición de una nueva forma de manifestación artística, los libros alternativos, nos cuestionamos ¿cuál es el origen de este término? ¿Qué son? ¿cómo se definen y representan los libros alternativos? Y ¿Qué materiales utilizan para su reelaboración o intervención? Actualmente, el uso de la tecnología, en general, y la elaboración de ciertos artefactos escriturales, como el libro es casi del dominio público, seamos alfabetizados o no, los hayamos tenido en nuestras manos o solo hayamos visto en librerías, escaparates comerciales, bibliotecas, entre otros lugares y espacios. Podemos, además, aventurarnos y mencionar que todos los sectores sociales sabemos lo que es un libro pues éste ha sido preconcebido con fines prácticos para registrar ideas y distintas formas del pensamiento, ya sea para preservarlas o difundirlas. El sector de los creadores no es la excepción también conoce y utiliza estos artefactos del conocimiento: "Todos los artistas contemporáneos han usado el libro para revelar sus ideologías estéticas adaptando todos los formatos, materiales y técnicas concebibles" (Crespo Martin, 2014).

Al libro como se le ha conocido desde la Edad Media hasta finales del Siglo XX, ya sea manuscrito o impreso, se le ha visto disminuido en su presencia cultural, social y económica en la medida que aparece un nuevo actor, el libro electrónico (también conocido como libro digital). En la discusión de las ventajas del libro impreso y el libro electrónico se ha abierto un debate, incluso hasta posturas extremas donde se argumenta que el libro tal cual se conoció por varios siglos desaparecería y sería reemplazado por el libro digital cuya lectura se hace mediante dispositivos electrónicos (computadoras, laptops, tabletas electrónicas, smartphones, por mencionar algunos dispositivos). Lo cierto es que, al igual que con la transición de otros objetos escriturales (de la tableta de arcilla al rollo de papiro, del papiro al libro manuscrito, del manuscrito al libro impreso) dichas piezas han tenido que convivir durante periodos de metamorfosis. Ante el hecho de una transición en el uso de libros impresos y electrónicos, aparece una nueva forma de manifestación cultural: el libro alternativo.

A partir de lo expuesto anteriormente, nos planteamos los siguientes objetivos de investigación: a) describir el proceso de transición del libro tradicional al libro alternativo; b) identificar los términos relacionados con el libro alternativo, y; c) referir los materiales utilizados en la elaboración de los libros alternativos como objetos escriturales. Para cumplir con las metas propuestas, el estudio se organizó de la siguiente manera: antecedentes del libro alternativo; el libro y el libro alternativo: anotaciones conceptuales; método y procedimiento; resultados: el libro como representación artística; discusión, y; conclusiones.

\section{Antecedentes del libro alternativo}

Algunos antecedentes de los libros alternativos los ofrece Bibiana Crespo Martin (2014) al enumerar artistas y algunas de sus obras: Giovanni Battista Piranesi (Carceri), Francico de Goya (Caprichos), William Blake (Songs of Innocence and of Experience), William Morris (The Ideal Book) y Stéphane Mallarmé (Un Coup de Dés). Respecto a Mallarmé, Marco Antonio Rangel González (2007), en la revisión histórica de su Tesis Los libros de artista, los otros libros, menciona un uso de "lo poético, lo visual, lo tipográfico y lo editorial" y se recurre como ejemplo a las tarjetas postales enviadas a su hermano en el Siglo XIX. Según Torres Barajas (2010), en esta época al libro alternativo, también se le llamó los otros libros o libros del arte nuevo. Recientemente, White Martínez (2002) afirma que los artistas han tenido "La preocupación... por renovar los libros, en donde está implícito el carácter plástico, en el manejo de técnicas y materiales con los cuales se experimenta...".

\section{Del libro manuscrito al libro impreso}

Los antecedentes del libro, o pre-libros como lo llama la comunidad académica de artistas plásticos, no eran precisamente un conjunto de hojas, pegadas, cocidas, engrapadas o unidas de alguna otra forma. Incluso, podían no tener la forma rectangular, o sus hojas estar protegidas por una cubierta o de algún tipo de encuadernación, así como ejemplos podemos mencionar las tablillas de madera, las tabillas enceradas, las tiras de bambú, las tablillas de marfil enceradas, los libros de metal, o los manuscritos en hoja de palma (Figura 1). 
Tablillas de madera enceradas
Tablillas de

marfil enceradas
Manuscritos en palmas con cubiertas de madera, pintadas

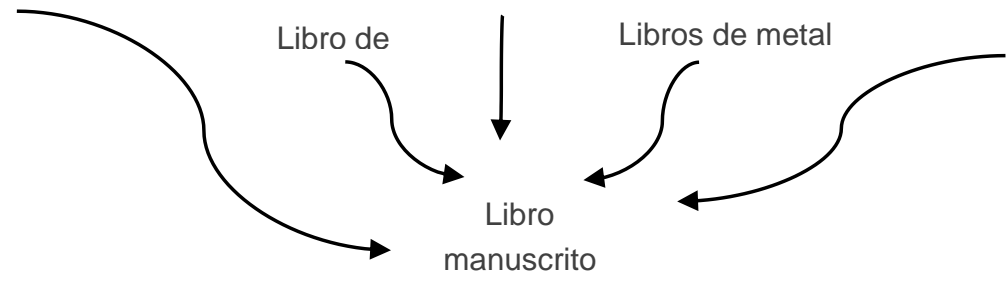

Figura 1. Antecedentes de los libros manuscritos, según el formato y definiciones actuales Fuente: El autor.

Si bien es cierto que los objetos que dieron origen al libro, ya sea de manera secuencial, y en otros momentos simultáneamente, a partir del manuscrito hasta como los conocemos en nuestros días, aceptado y reconocido socialmente como un instrumento que genera saberes, se le ha dado un valor más allá del económico: culto, poder (control, liberación), por mencionar algunos.

\section{El libro y el libro alternativo: anotaciones conceptuales}

El término libro tiene tantas definiciones como disciplinas del conocimiento existen, cada una de ellas se vincula de acuerdo a los perfiles, intereses u objetivos de las fuentes, estudiosos o investigadores. Para fines de este artículo, y solo de carácter indicativo, se han escogido algunas enunciaciones, tanto del dominio público, del ámbito técnico o el enfoque especializado en las artes. En cuanto al dominio público, el Diccionario de la lengua española de la Real Academia de la Lengua [RAE] (2012) define al libro en varias acepciones, una de las cuales es aquella que nos señala que es un "Conjunto de muchas hojas de papel u otro material semejante que, encuadernadas, forman un volumen”. Por su parte, en relación a las fuentes de conocimiento técnico, el Diccionario de bibliología y ciencias afines: terminología relativa a archivística, artes e industrias gráficas, bibliofilia, bibliografía, bibliología, bibliotecología, biblioteconomía de José Martínez de Sousa (2004) indica que libro es un:

\footnotetext{
...conjunto de hojas de papel, papiro, pergamino, vitela, u otra materia escriptórea, manuscritas o impresas, reunidas en el lomo por medio de cosido, encolado, anillado, etcétera, con cubierta de madera, cartón, cartoncillo, pergamino, cartulina, papel u otro material, formando un volumen.
}

Finalmente, una fuente especializada en las artes, The dictionary of art, editada por Jane Turner (1996), señala que el libro es un objeto portable para almacenar información para ser transmitida como escritura, anotaciones, pinturas o fotografías los cuales han sido inscritos a mano o impresos. El vertido de estos tres ejemplos de definición de libro, de los dominios público, técnico o especializado en las artes, es únicamente con fines indicativos, es decir para concluir que el concepto puede ser tan abreviado o tan amplio como las fuentes de información que se consultan.

En ciertas comunidades u organismos (bibliotecarios y bibliotecas, respectivamente), para diferenciar los libros de otros materiales impresos, los delimitan por cierta cantidad de páginas, hasta cincuenta para los folletos y mayor a esta cantidad para los libros. El concepto libro tiene distintas aristas, su definición depende del área del conocimiento que lo defina; el gremio de las artes hace lo suyo, solo por mencionar un enunciado, "...un libro es una secuencia de páginas, momentos y tiempos..." (Martorano Sánchez, 2003). Por otra parte, libro alternativo es de cuño reciente y tiene su origen en distintas iniciativas y momentos, por ejemplo, las acepciones de... "libros ilustrados, libros de artista, libros objeto y libros híbridos" (Calderón Montellano, 1997). Los libros alternativos, principalmente desde finales del Siglo XX y principios del XXI, han sido motivo de análisis, preparación e incluso en la descripción y manufactura por entidades académicas como la Escuela Nacional de Artes Plásticas de la Universidad Nacional Autónoma de México en sus distintos talleres y seminarios.

La necesidad de nuevas formas de manifestación artística retoma la forma y algunos elementos que componen al libro tradicional (papel, texto) para el diseño, entramado, elaboración o modificación de nuevas maneras de expresión, añadiendo otros elementos, el uso de nuevos materiales, por ejemplo. Las variantes del libro alternativo, derivadas del libro convencional, a partir de la intervención del artista: 
...son una propuesta diferente en relación a lo convencional ya que el autor lo crea con entera libertad, se permite experimentar con los materiales que soportan las ideas y rompe con que sea únicamente en papel, busca nuevas formas de impresión, la tipografía toma un nuevo valor... (Cárdenas Herrera, 2010).

Para fines de nuestra investigación se entenderá como libro alternativo:

... una forma de libro... [el cual] no se restringe al uso de un solo soporte como lo sería el papel o a un único formato como un libro...en él se recurre a todo tipo de materiales -nuevos o de reciclaje, suaves o rígidos, geométricos o irregulares, perdurables o efímeros-, cuyas dimensiones, presentación y formato no tienen restricción alguna." (Ruíz Marcelo, 2005).

\section{Método y procedimiento}

Estudio descriptivo, cuyo procedimiento fue tanto la investigación documental como de campo. De la investigación documental se configuraron criterios de búsqueda en bases de datos especializadas en ciencias sociales y humanidades, y el buscador en Internet (Google Scholar) de acuerdo a los siguientes términos. A partir de estrategias de búsqueda asociadas al conjunto "libro alternativo", se procedió a la recuperación de documentos relativos a los tópicos: "libro de artista", "libro objeto", "libro de arte", "libro caja objeto", "libro alternativo infantil", "libro de viaje alternativo", "libro litográfico alternativo", "libro gráfico alternativo", "libro objeto gráfico alternativo" y "libro objeto didáctico". En relación al trabajo de campo, se visitaron museos, exposiciones o eventos del mundo del libro. Posteriormente, se procedió a la colección, lectura y análisis, tanto de los documentos recuperados y la selección de ejemplos de obras expuestas, lo cual derivó en la redacción de los resultados, la discusión y las conclusiones.

\section{Alcances, limitaciones y propuestas de otras investigaciones}

La investigación de primera aproximación, no es un estudio iconográfico y los ejemplos son una selección que no representa una muestra científica pero sí es indicativa para encontrar los antecedentes, las variantes de formato y el uso de distintos materiales para la elaboración del libro alternativo. Futuras investigaciones. No se abunda en los antecedentes de cada una de las variantes de los términos asociados al libro alternativo, puesto que ya lo hicieron los autores referenciados al final de este artículo, sin embargo, los resultados de esa relación de términos conexos puede ser un detonante para futuras investigaciones. No obstante los resultados y las conclusiones de nuestro estudio, es posible plantear preguntas para continuar y profundizar en el futuro acerca de si ¿el libro alternativo, dará un salto para la composición de nuevas formas de expresión utilizando las tecnologías de la información y la comunicación?, o si ¿La comunidad de artistas plásticos le seguirán llamando libro electrónico, libro electrónico intervenido, libro electrónico híbrido, libro electrónico de artista, o alguna otra adjetivación?, o bien, ¿Será el libro alternativo virtual el siguiente competidor, o complemento, del libro alternativo?

\section{Resultados: el libro como representación artística}

El libro manuscrito y posteriormente el libro tradicional son el preámbulo, motivación e inspiración de las comunidades dedicadas al diseño y la creación del libro alternativo. Mientras se realizaba la búsqueda del concepto libro alternativo, se encontraron y se categorizaron los siguientes términos (Figura 2):

1) Libro objeto (Colín Samperio, 2010; Contreras Valadez, 2014; Cruz Catarino, 2012; López Castro, 2005; Pichardo Flores, 2005; Méndez Tejeda, 2009; Rocha Valverde, 2004; Ruíz Marcelo, 2005; Unzueta Tonks, 2009; White Martínez, 2002), libro-objeto, libro-objeto infantil y libro objeto de fotografías.

2) Libro alternativo (Alarcón González, 2014; González Naranjo, 2009; Martorano Sánchez, 2003; Torres Barajas, 2010), libro alternativo infantil (Cárdenas Herrera, 2010), libro infantil alternativo (Rosales Argonza, 1997), libro de viaje alternativo (Estrada Sánchez, 2008), libro litográfico alternativo (Villalpando Loredo, 2003), libro gráfico alternativo (Calderón Montellano, 1997), libro alternativo-gráfico (Bernal Fernández, 1994), libro objeto gráfico alternativo (González de Hoyos, 
1996), libro objeto didáctico alternativo (Sánchez Montiel, 1996) y libro alternativo virtual 3-D (Pérez Martínez, 2009);

3) Libro de artista (Moros, 2010; Contreras Castillo, 2014; Crespo Martin, 2014; Vilchis Esquivel, 2009), libros de artista (Rangel González, 2007), libros de artistas, libro de artista-gráfico;

4) Libro híbrido (Rojas Cuevas, 2001; Zenteno Calderón, 2005);

5) Libro de artista cerámico, y;

6) Libro intervenido (Moros, 2010).



Figura 2. El libro como representación artística

Fuente: El autor.

A continuación, se presenta una selección de libros alternativos con algunas de sus variantes en cuanto a materiales, tipo de intervención, la disposición de libros para las exposiciones (instalaciones), o en su defecto, la separación de alguna de sus partes para conformar un nuevo objeto, o bien, el acompañamiento de otros materiales u objetos, incluso, hasta situaciones en las que el libro pierde su forma o en casos extremos se aprecia una disminución visual de la escritura.

\subsection{El libro alternativo intervenido}

El libro intervenido, según Luis Moros (2010), “... trata de tomar un libro cualquiera y trabajar sobre él, a la manera de un palimpsesto, para producir un nuevo objeto, esta vez estético, cuya soberanía ha perdido toda importancia" y su característica principal es que se trabaja sobre él para dar origen a una nueva pieza en las cuales se utiliza solo un ejemplar y se distinguen porque el artista hizo algunas fisuras, o recortes. Entre algunos ejemplos podemos mencionar las obras: Volume 16: Process de Donna Ruff, The medium is the message de Robert The y Ryoanij de Guy Laramé. Un caso más de libro alternativo intervenido es El libro de las lamentaciones del artista plástico José Antonio Hernández Vargas. La obra pertenece a la colección del Instituto Nacional de Bellas Artes y se exhibió en el Museo de Arte Carrillo Gil en 2015 (Foto 1). 




Foto 1. Libro alternativo intervenido El libro de las lamentaciones por José Antonio Hernández Vargas Fuente: El autor.

\subsection{Los libros alternativos e instalaciones}

Las instalaciones son otra categoría en la cual encontramos libros alternativos y su característica principal es que no han sido intervenidos sino acomodados intencionalmente de tal manera que conforman un conjunto. De la obra Book art: iconic sculptures and installations made from books, editada por Paul Sloman (2011), se pueden mencionar los siguientes ejemplos: Biografías de Alicia Martin, pieza presentada en el Palacio Linares, Casa de las Américas en Madrid, España y Book Cell de Matej Krén, instalada en el Centro de Arte Moderno de la Fundación Calouste Gubenkian en Lisboa, Portugal. En el primer ejemplo los libros se muestran con cierto orden y en el segundo ejemplo se observan desparramados. Un caso más es la instalación Wrong way time de Fiona Hall presentado en el 57th International Art Exhibition, la Biennali di Venezia, Pabellón australiano, 2015, cuya obra muestra un cúmulo de libros, semi-organizados verticalmente, más una pieza de reloj (Foto 2). 


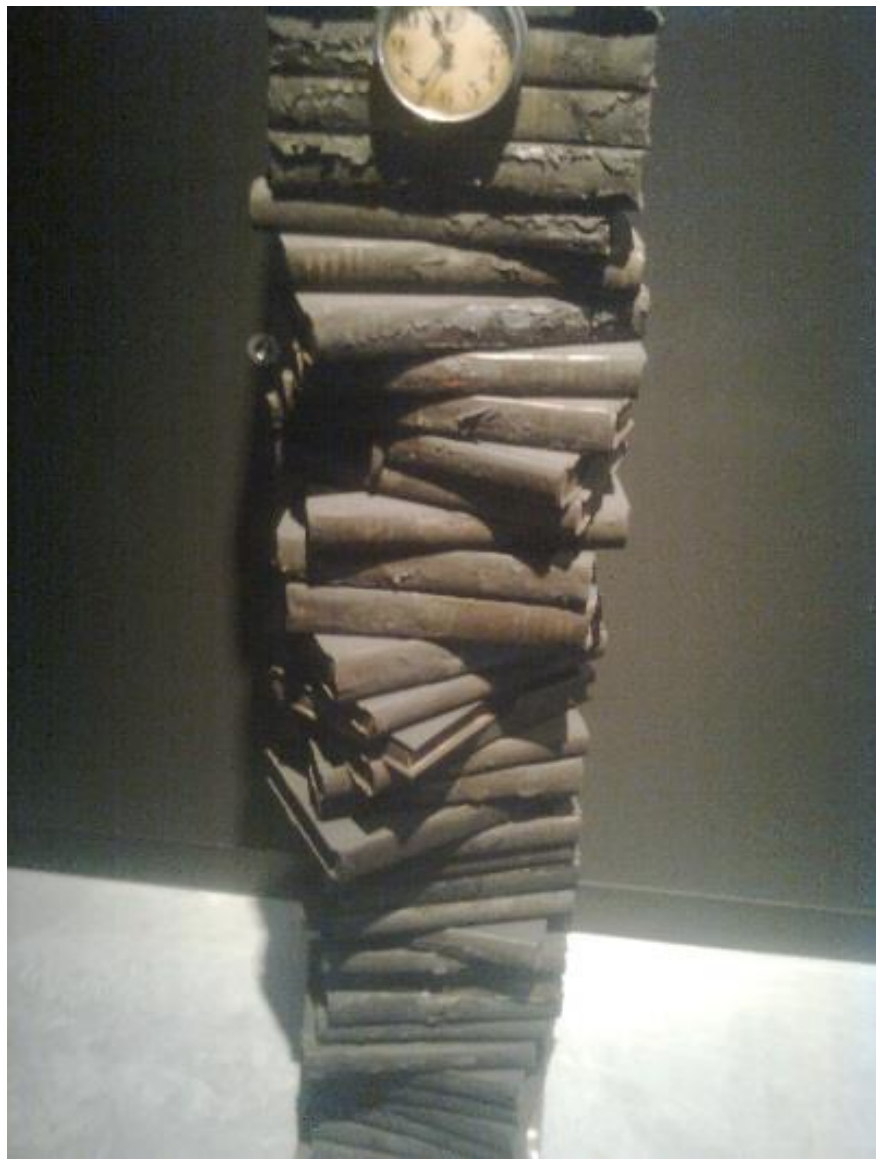

Foto 2. Wrong way time, Fiona Hall

Fuente: El autor.

\subsection{Los libros alternativos con agregaciones o disgregaciones}

A continuación, podemos mencionar aquellos libros que "no son libros", o más bien están dejando de serlo. Son objetos que han sido modificados, han sido intervenidos y una o varias de sus partes han sido separadas (Swiss army book), o con la variante de añadir otras piezas ajenas a la original (Egg-plant). Otros ejemplos, son Braque de Robert The en la cual al libro se le recorta una parte en forma de escorpión y The meaning of art de Ros Rixon que contiene tiras de papel a manera de separadores. Una obra similar a la de Rox, ¿Es-tu comme moi?, de Donna Ruff, conecta dos libros mediante tirillas textuales. Un último ejemplo es el que menciona Luis Moros (2010) en su artículo "El libro de artista y el libro intervenido: un análisis semiótico" donde hace alusión al Libro Preguem de Josep Asunción y Gemma Guash en el cual se muestran hojas con espacios vacíos, donde alguna vez hubo texto (palabras, líneas, e incluso párrafos completos).

\subsection{Los libros alternativos: libros de artista o libro de artista único}

El libro de artista, según Moros (2010) consiste “...en encuadernar una serie de dibujos, bocetos, manchas de color, trazos, recortes, ejercicios plásticos de todo tipo en materiales diversos, con la intención de presentarlos bajo la forma socialmente aceptada de un libro" y van sumando nuevas técnicas para su elaboración, así como la inclusión de elementos materiales escriturales diversos: placas, fotograbados manipulados (The diary of a sparrow); paños bordados (Endangered species); hierro, latas, tapas (Litolattine); collage (She has vanished from the outside and gone within...). Otro ejemplo es la obra Llibre de fusta de Jaume Plensa (2004), protegida con una cubierta de madera y conformado por once xilografías a tres colores. Una característica de las piezas es que aún mantienen un formato rectangular, rasgo que identifica a la mayoría de los libros tradicionales. Sin embargo, esto no siempre es así, el libro de artista también puede cambiar, tanto en su forma como en los materiales utilizados. 


\subsection{Del libro al no libro: el libro pierde su forma (rollo, cajas, etc.)}

La comunidad artística lanza, defiende, propone y redefine visualmente al libro; nace el no libro, es decir el libro que pierde casi totalmente su forma, volumen, geometría, la sujeción de páginas u otros materiales para dar paso a objetos distintos al libro tradicional (hojas plegables, rollo, cajas, libros macerados, entre otros ejemplos).

\subsubsection{Los libros alternativos plegables}

Los libros plegados se distinguen porque son piezas en forma de biombo, contienen una cubierta al igual que los libros tradicionales, por ejemplo, las obras On this land de Karen Kunc, Endangered species de Lois Morrison y The diary of a sparrow de Kazuko Watanabe. Este tipo de objetos se conforman con materiales varios, como xilografías sobre papel, nogalina en papel, o bien paño con dibujos a lápiz o impresiones (Wasserman, 2011). Otros casos de uso de múltiples materiales son The diary of a sparrow, hecho con planas en aguafuerte de color e imágenes impresas en computadora y La infiel de Magali Lara y Carmen Boullosa. Esta segunda pieza forma parte de la Colección del Instituto Nacional de Bellas Artes y se exhibió en el Museo de Arte Carrillo Gil en 2015 (Foto 3). La obra se compone de tres piezas plegables más una hoja suelta y en una de éstas se observan datos como "Editorial La tercera parte de la noche México D.F. 1987". Un ejemplo más de libro plegable es la obra Llibre de vidre (i.e. Libro de vidrio) de Jaume Plensa (2004) que está conformado por 16 placas de vidrio con impresión en serigrafía y la cual presenta palabras o enunciado.

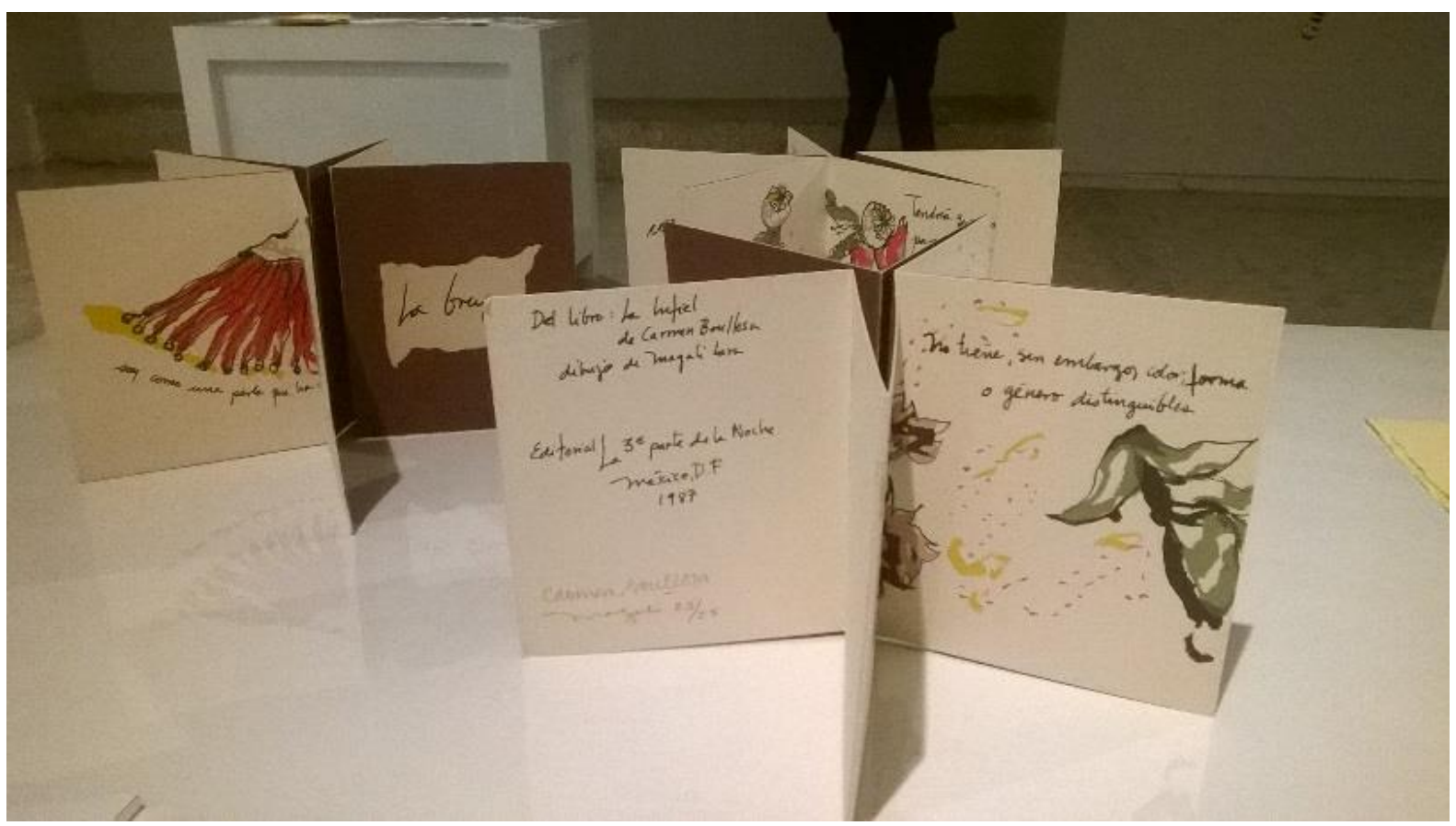

Foto 3. La infiel de Magali Lara y Carmen Boullosa

Fuente: El autor.

\subsubsection{Los libros alternativos adoptan nuevas formas}

Los libros alternativos en forma de rollo no son nuevos, recordemos que por mucho tiempo el papiro era usado por los egipcios y los romanos hasta la aparición de los códices. En la actualidad, el papel y otros elementos son requeridos para la elaboración de libros alternativos. Por ejemplo, M. Jordan Tierney quien en la pieza She kepps her secrets in an amber jar so the light won't fade them utiliza acrílico, pintura de aerosol, grafito, papel, madera y vidrio (Wasserman, 2011). Por otra parte, los libros adoptan la forma de caja. Así podemos mencionar la obra de Allison Brown, Teatimes, 2005, en la cual se muestra una caja cubierta de ceda y forro de papel y dentro de ésta varias muestra como bolsitas de té (Wasserman, 2011). Por otro lado, otra muestra de las mutaciones librescas es la obra Room for improvemente de Lisa Kokin, o Following: new books of knowledge de Brian Dettmer donde se muestra un conjunto de libros que conformaban una enciclopedia totalmente doblados, deformando su composición original, cuyas muestras textuales son casi imperceptibles. El libro pierde casi totalmente su forma, a reserva de algunos contenidos textuales ese objeto ha sido mojado, macerado, redondeado y casi reducido a uno de los estados originales del papel: la pulpa. Así podemos mencionar como 
ejemplo la obra Room for improvemente de Lisa Kokin, o Following: new books of knowledge de Brian Dettmer donde se muestra un conjunto de libros que conformaban una enciclopedia totalmente doblados, deformando su composición original, donde apenas se perciben muestras textuales.

\section{Discusión}

Consideramos que la culminación, o más bien la propuesta, del libro alternativo como expresión artística tiene su origen en dos aspectos, el primero, en los procesos de transición del libro manuscrito al libro impreso, mientras que el segundo, en la consideración del libro tradicional como objeto de arte. Si bien es cierto que, como resultado del presente estudio se muestra una evolución conceptual y denominativa del libro alternativo, cuyos antecedentes son el libro tradicional (o convencional) y el libro objeto (o el libro de artista), es posible identificar que a partir de ese concepto, libro alternativo, encontramos una diversificación terminológica de origen: libro intervenido, libro híbrido, libro alternativo infantil, libro de viaje alternativo, libro litográfico alternativo, libro gráfico alternativo, libro objeto gráfico alternativo, libro objeto didáctico, por mencionar algunos ejemplos. Por otro lado, verificamos que el término libro objeto se mantiene, y cada vez hay mayores consensos en denominar a éste y al conjunto de elementos listados en este párrafo como libro alternativo (Figura 3).

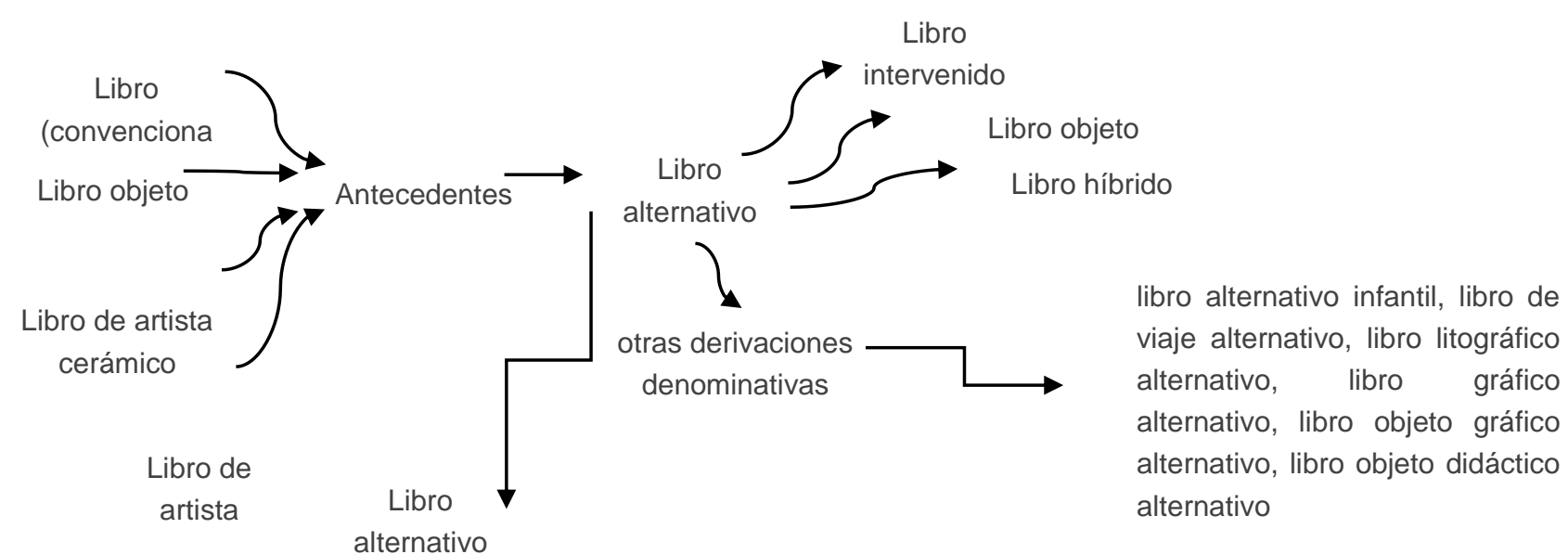

Figura 3. Evolución conceptual y denominativa del libro alternativo

Fuente: El autor.

Por un lado, se observa que las transformaciones, deformaciones (agregaciones o desagregaciones) del libro alternativo no son nuevas. De hecho, los antecedentes del libro tradicional tuvieron una conformación paulatina. En un principio los libros manuscritos no contenían cubiertas como las actuales, o bien estaban dispuestos por un conjunto de pergaminos en forma de biombo. Por otra parte, los libros impresos no contenían las partes como las conocemos ahora (colofón, la página legal, los índices, por mencionar algunos). La conformación del libro convencional fue gradual hasta la forma tal cual lo conocemos. Sin embargo, si revisamos el trecho temporal, desde su nacimiento hasta nuestros días, aceptamos el término libro, le creamos respeto, culto y valores. Desde que conocemos al libro manuscrito y posteriormente el libro impreso, su uso cotidiano detonó una aceptación social del término libro. Tan es así que objetos que no tienen el formato tradicional tanto en su forma y elementos materiales se les ha añadido la denominación libro, por ejemplo: libro pagoda, Libro de Ester, Libro de los muertos, libro en forma de vasija, libro esférico, o como se menciona en el artículo "Los códices prehispánicos y novohispanos en Mesoamérica como objetos de la escritura”, libros plegables aztecas (Martínez Musiño, 2015a) (Figura 4). 


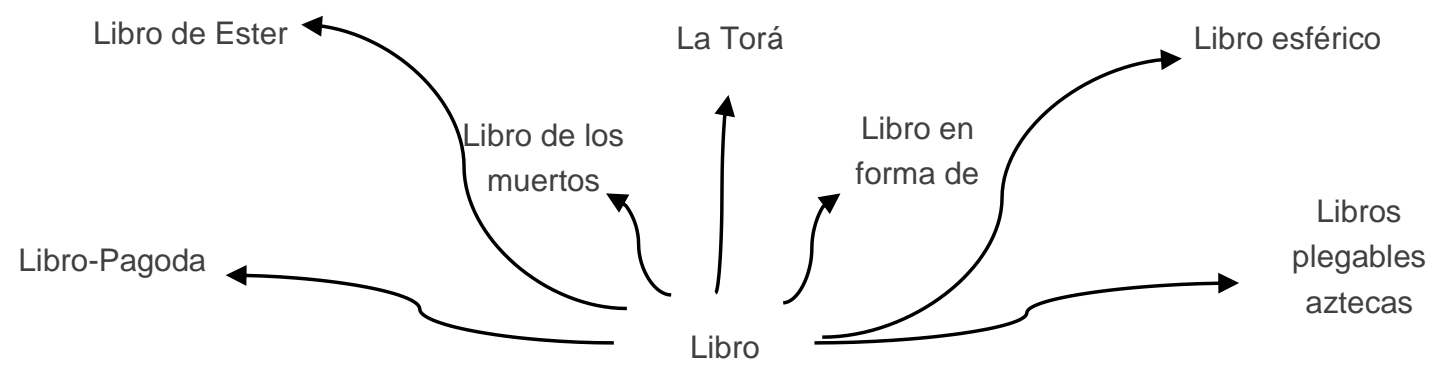

Figura 4. El libro manuscrito, según la importancia histórica religiosa, sin contar con las definiciones actuales del libro

Fuente: El autor.

Entonces, tanto en el pasado como en el presente, el libro, generalmente elaborado a base de papel, con formato rectangular, con sus respectivas cubiertas, hojas guarda, etc., tuvo y tiene sus acepciones visuales.

\section{Conclusiones}

Las conclusiones se organizan de acuerdo a los objetivos planteados. Así, tenemos respecto al primer objetivo, describir el proceso de transición del libro tradicional en el libro (alternativo), lo siguiente: a) se observan nuevas formas artísticas que retoman al libro tradicional (impreso) como punto de origen; b) el formato del libro tradicional en la conversión del libro alternativo se puede mantener, extraer alguna de sus partes, sumar otros libros, técnicas y materiales o en su defecto convertirse en un nuevo objeto sin la forma convencional: el libro tradicional; c) la escritura en los libros alternativos puede o no mantenerse, mostrar solo una parte del todo o diluirse totalmente; d) el libro alternativo puede ser una pieza tradicional, o bien adicionar otras del mismo género.

En relación al segundo objetivo, identificar los términos relacionados con el libro objeto, podemos decir lo siguiente: d) las manifestaciones artísticas retoman la etapa del pre-libro como manifestación de punto de partida, o en su defecto, modificar las formas previas del libro manuscrito y el libro convencional; e) se registran variaciones terminológicas, adjetivadas, respecto al libro (híbrido, objeto, alternativo, entre otros) sin cambios en la denominación del sujeto (libro); f) el libro, según los datos encontrados adapta su denominación a documentos del pasado y se adopta como concepto a la actividad artística (artes visuales: comunicación gráfica, diseño y comunicación visual, por mencionar algunas áreas del conocimiento creativo).

En tanto al tercer objetivo, referir los materiales utilizados en la elaboración de los libros alternativos como objetos escriturales, concluimos lo siguiente: g) los libros alternativos rompen, parcial o completamente, con el formato del libro tradicional; h) los materiales de los libros alternativos complementan, sugieren y experimentan nuevos materiales escriturales, incluso los mixturan; i) los libros alternativos, al igual que el libro tradicional, se adaptan, o adoptan las tecnologías de la información y la comunicación, así podemos observar la presentación de nuevos 'objetos' en 3-D (tridimensionales); j) la libertad en el uso de materiales es tan basta como la imaginación, el ingenio y la innovación humana para la creación, la contemplación y el disfrute de las obras de arte. 


\section{Referências}

Alarcón González, F. (2014). Cordis Epístola: reflexiones semiológicas en torno a la construcción del libro alternativo. México: El autor. Tesis-Maestría en Artes visuales (Universidad Nacional Autónoma de México, Facultad de Arte y Diseño). Recuperado de http://132.248.9.195/ptd2014/noviembre/096004906/Index.html

BernaL Fernández, R. (1994). Seres híbridos y mitológicos: libro alternativo-gráfico. México: El autor. Tesis-Licenciado en Artes Visuales (Universidad Nacional Autónoma de México. Escuela Nacional de Artes Plásticas).

Calderón Montellano, M. M. (1997). La danza azteca guerrera: libro gráfico alternativo. México: La autora. Tesis-Licenciatura en Artes Visuales (Universidad Nacional Autónoma de México. Escuela Nacional de Artes Plásticas). Recuperado de http://132.248.9.195/ppt2002/0251545/Index.html

Cárdenas Herrera, M. M. (2010). Diseño del libro alternativo infantil: un paseo por el cielo. México: La autora. TesisLicenciatura en Diseño y Comunicación visual (Universidad Nacional Autónoma de México, Facultad de Estudios Superiores Cuautitlán). Disponible en: http://132.248.9.195/ptb2011/abril/0668019/Index.html

Colín Samperio, E. (2010). Memoria gráfica (de un burro de planchar): libro objeto. México: La autora. Tesis-Licenciatura en Artes Visuales (Universidad Nacional Autónoma de México, Escuela Nacional de Artes Plásticas). Recuperado de http://132.248.9.195/ptb2010/octubre/0663739/Index.html

Contreras Castillo, B. (2014). Libro de artista a partir de la gráfica. Xalapa, Veracrúz: La autora. Trabajo práctico artísticoLicenciada en Artes Visuales (Universidad Veracruzana)

Contreras Valadez, B. C. (2014). Amoxtli tlamantli libro objeto. México: La autora. Tesis-Licenciatura en Comunicación Gráfica (Universidad Nacional Autónoma de México, Escuela Nacional de Artes Plásticas). Recuperado de http://132.248.9.195/ptd2014/marzo/092134010/Index.html

Crespo Martin, B. (2014). El Libro de Artista de ayer a hoy: seis ancestros del Libro de Artista contemporáneo: primeras aproximaciones y precedentes inmediatos. Arte, Individuo y Sociedad, 26(2), 311-328.

Cruz Catarino, O. (2012). Elaboración de imágenes sobre la desigualdad y represión aplicadas en diseño editorial de libro objeto. México: La autora. Tesis-Licenciatura en Diseño y Comunicación Visual. (Universidad Nacional Autónoma de México, Escuela Nacional de Artes Plásticas). Recuperado de http://132.248.9.195/ptd2012/junio/303052344/Index.html

Estrada Sánchez, M. L. (2008). Libro (de viaje) alternativo en la Ciudad de México. México: La autora. Tesis-Licenciatura en Artes visuales (Universidad Nacional Autónoma de México, Escuela Nacional de Artes Plásticas). Recuperado de http://132.248.9.195/ptd2008/julio/0629275/Index.htm/

González de Hoyos, Y. K. (1996). Libro objeto gráfico alternativo: luminiscencias marinas. México: La autora. Tesis-Licenciado en Diseño Gráfico (Universidad Nacional Autónoma de México. Escuela Nacional de Artes Plásticas).

González Naranjo, J. J. (2009). Antes y después del cimiento: espacios inconclusos vistos desde un libro alternativo. México: El Autor. Tesis-Licenciatura en Artes visuales (Universidad Nacional Autónoma de México, Escuela Nacional de Artes Plásticas). Recuperado de: http://132.248.9.195/ptd2009/febrero/0639643/Index.html

López Castro, A. G. (2005). Lotería grafica taurina: libro objeto. México: La autora. Tesis-Licenciatura en Artes visuales (Universidad Nacional Autónoma de México, Escuela Nacional de Artes Plásticas). Recuperado de http://132.248.9.195/ptb2005/00225/0347263/Index.html

Martínez de Sousa, J. (2004). Diccionario de bibliología y ciencias afines: terminología relativa a archivística, artes e industrias gráficas, bibliofilia, bibliografía, bibliología, bibliotecología, biblioteconomía. 3ª ed. Gijón: Trea

Martinez Musiño, C. (2015a). Los códices prehispánicos y novohispanos en Mesoamérica como objetos de la escritura. Bibliotecas. Anales de Investigación, (11), 32-49. Recuperado de http://revistas.bnim.cu/index.php/anales/article/view/3384/3140

Martínez Musiño, C. (2015b). Los soportes, las superficies y los visualizadores de la escritura: enfoques y materiales. DataGramaZero - Revista de Informação, 16(6). Recuperado de http://eprints.rclis.org/28796/1/Lossoportes\%2Clas\%20superficiesylosvisualizadoresdelaescritura.pdf

Martorano Sánchez, E. I. (2013). Cuento: Libro alternativo. México: La autora. Tesis-Licenciatura en Artes visuales (Universidad Nacional Autónoma de México, Escuela Nacional de Artes Plásticas). Recuperado de http://132.248.9.195/ppt2002/0326889/Index.html

Méndez Tejeda, B. (2009). Paseo de la Reforma: percepción de su arquitectura en un libro objeto. México: La autora. TesisLicenciatura en Artes visuales (Universidad Nacional Autónoma de México, Escuela Nacional de Artes Plásticas). Recuperado de http://132.248.9.195/ptd2009/marzo/0641407/Index.htm

Moros, L. (2010). El libro de artista y el libro intervenido: un análisis semiótico. Fermentum, (57), 151-170. Recuperado de http://www.saber.ula.ve/bitstream/123456789/33262/1/articulo9.pdf 
Pérez Martínez, J. F. (2009). ABC del espacio-tiempo en dibujo, animación y mecánica de Meggendorfer, Nister, Tuck, Reynaud, Muybridge y Marey: libro alternativo virtual 3-D. México: El autor. Tesis-Maestría en Artes Visuales (Universidad Nacional Autónoma de México. Escuela Nacional de Artes Plásticas). Recuperado de http://132.248.9.195/ptd2009/octubre/0649580/Index.html

Pichardo Flores, E. D. (2005). Post mortem finis: libro objeto. México: El autor. Tesis-Licenciatura en Artes visuales (Universidad Nacional Autónoma de México, Escuela Nacional de Artes Plásticas). Recuperado de http://132.248.9.195/ptb2005/00225/0346344/Index.htm/

Plensa, J. (2004). Jaume Plensa: libros, grabados y múltiples sobre papel = books, prints and multiples on paper: 1978-2003. Valencia: Fundación César Manrique.

RangeL González, M. A. (2007). Los libros de artista, los otros libros. México: El autor. Tesis-Maestro en Artes Visuales con Orientación en Pintura (Universidad Nacional Autónoma de México, Escuela Nacional de Artes Plásticas). Recuperado de http://132.248.9.195/pd2007/0620926/Index.html

Real Academia Española [RAE] (2012). Libro. Diccionario de la lengua española. Ed. 22. Madrid: RAE. Recuperado de http://lema.rae.es/drae/?val=libro

Rocha Valverde, C. (2004). El libro objeto como producción editorial autogestiva: del objeto libro al libro objeto. México: La autora. Tesis-Licenciatura en Diseño Gráfico (Universidad Nacional Autónoma de México, Escuela Nacional de Artes Plásticas). Recuperado de http://132.248.9.195/ppt2004/0328855/Index.html

Rojas Cuevas, R. M. (2001). Registros de una ciudad olvidada que brotan de un libro híbrido. México: La autora. TesisLicenciado en Artes Visuales (Universidad Nacional Autónoma de México, Escuela Nacional de Artes Plásticas). Recuperado de http://132.248.9.195/pd2001/297956/Index.html

Rosales Argonza, M. (1997). En busca del sol: libro infantil alternativo. México: La autora. Tesis-Licenciatura en Artes Visuales (Universidad Nacional Autónoma de México, Escuela Nacional de Artes Plásticas). Recuperado de http://132.248.9.195/ppt2002/0251758/Index.html

Ruíz Marcelo, F. (2005). Artefacto: la morfología de la maquina en un libro objeto. México: El autor. Tesis-Licenciatura en Artes Visuales (Universidad Nacional Autónoma de México, Escuela Nacional de Artes Plásticas). Recuperado de http://132.248.9.195/ptb2005/00225/0345431/Index.html

Sánchez Montiel, J. R. (1996). El proceso de la vida: libro objeto didáctico alternativo. México: El autor. Tesis-Licenciado en Artes Visuales (Universidad Nacional Autónoma de México. Escuela Nacional de Artes Plásticas).

Sloman, P., ed. (2001). Book art: iconic sculptures and installations made from books. Berlin: Gestalten.

Torres Barajas, J. V. (2010). "El Sutra de los proverbios": libro alternativo de reflexión. México: El autor. Tesis-Licenciatura en Artes visuales (Universidad Nacional Autónoma de México, Escuela Nacional de Artes Plásticas). Recuperado de http://132.248.9.195/ptb2010/noviembre/0665087/Index.html

Turner, J., ed. (1996). Book. En The dictionary of art: vol. 4. New York: Grove.

Unzueta Tonks, R. (2009). Chalchiuhtlicue, sirena azteca, libro objeto. México: La autora. Tesis-Maestría en Artes visuales con orientación en Pintura (Universidad Nacional Autónoma de México, Facultad de Arte y Diseño). Recuperado de http://132.248.9.195/ptd2009/octubre/0650307/Index.html

Vilchis Esquivel, L. C. (2009). Las lecturas ajenas: el libro de artista Revista intercontinental de psicología y educación, 11(2), $91-100$.

Villalpando Loredo, M. G. (2003). Lectura lú-dica [sic]: recreando el presente y pasado, en un libro litográfico alternativo. México: La autora. Tesis-Licenciado en Artes Visuales (Universidad Nacional Autónoma de México. Escuela Nacional de Artes Plásticas). Recuperado de http://132.248.9.195/ppt2002/0326357/Index.html

Wasserman, K. (2011). The book as art: artists' books from the National Museum of Women in the arts. 2a. ed. New York: Princeton Architectural Press.

White Marines, C. (2002). La creación de un libro objeto aplicada a la leyenda de los vampiros. México: La autora. TesisLicenciatura en Artes visuales (Universidad Nacional Autónoma de México, Escuela Nacional de Artes Plásticas). Recuperado de http://132.248.9.195/ppt2002/0312253/Index.htm|

Zenteno Calderón, V. Y. (2005). Vírgenes apocalípticas: iconografía mariana en un libro híbrido. México: La autora. TesisLicenciado en Artes Visuales (Universidad Nacional Autónoma de México, Escuela Nacional de Artes Plásticas). Recuperado de http://132.248.9.195/ptb2005/00225/0340762/Index.html 


\section{Datos del autor}

\section{Celso Martínez Musiño}

Investigador y consultor. Diplomado en Acción y Desarrollo Cultural por el Museo Nacional de San Carlos, y Espacio Espiral (México). Maestro y Licenciado en Bibliotecología por El Colegio de México y la Universidad Nacional Autónoma de México (UNAM), respectivamente. Doctor por la Universidad de Zaragoza y la UNAM. cmartinez@colmex.mx

Recibido - Received: 2016-05-11

Aceptado - Accepted: 2016-10-21

\section{(c) $)$ EY}

This work is licensed under a Creative Commons Attribution 4.0

United States License.

\section{ULLS D-Sorke}

This journal is published by the University Library System of the University of Pittsburgh as part of its D-Scribe Digital Publishing Program and is cosponsored by the University of Pittsburgh Press. 